\title{
TURBULENT EDDY DIFFUSIVITIES FOR A PLANETARY BOUNDARY LAYER GENERATED BY THERMAL AND MECHANICAL EFFECTS
}

\author{
André Becker Nunes ${ }^{1}$, Gervásio Annes Degrazia², \\ Cláudia Rejane Jacondino de Campos ${ }^{1}$ and Davidson Martins Moreira ${ }^{3}$
}

\begin{abstract}
To estimate the superficial concentration of contaminants an eulerian model of dispersion was used, where the main scheme is the diffusion-advection equation that employs turbulent eddy diffusivity. The aim of this work is a comparison between different eddy diffusivity derivations for a planetary boundary layer turbulence generated by thermal and mechanical effects. The accuracy of eddy diffusivity derivations was evaluated by comparing the data simulated in the eulerian dispersion model and the observed concentrations of the Copenhagen and Praire Grass experiments. Three convective eddy diffusivity derivations were compared among themselves: 1) proposed by Degrazia et al., 2) proposed Hostlag \& Moeng and 3) the derivation gotten by the parameters of Hanna. Two neutral eddy diffusivity derivations were also compared: 1) proposed by Degrazia et al. and 2) gotten by the parameters of Hanna. In order to improve the comparisons some adjustments and increments were made in Hostlag \& Moeng derivation and in that gotten by the parameters of Hanna. We can observe that despite the eddy diffusivities having been formulated by different ways, the results were similar and sufficiently satisfactory. In the convective case, the best simulations of each derivation showed a Normalized Mean Squared Error between 0.04 and 0.05 when compared with Copenhagen dataset.
\end{abstract}

Keywords: dispersion model, Taylor theory, lagrangean timescale.

RESUMO. Na estimativa da concentração superficial de contaminantes foi usado um modelo de dispersão euleriano, tendo como esquema principal a equação de difusão-advecção que emprega coeficiente de difusão turbulento. 0 objetivo deste trabalho é a comparação entre diferentes derivações de coeficientes de difusão para uma camada limite planetária cuja turbulência é gerada por fatores térmicos e mecânicos. A precisão das derivações foi calculada por meio da comparação entre os dados simulados pelo modelo euleriano de dispersão e os dados de concentração observados nos experimentos de Copenhagen e Praire Grass. Três derivações de coeficientes de difusão convectivos foram comparadas: 1) a proposta por Degrazia et al., 2) a proposta por Hostlag \& Moeng, e 3) a derivação obtida através dos parâmetros de Hanna. Também foram comparadas duas derivações de coeficientes de difusão neutros: 1) uma proposta por Degrazia et al. e 2) a obtida por meio dos parâmetros de Hanna. Para uma melhor comparação, foram feitos alguns ajustes nas derivações de Hostlag e Moeng e na obtida através dos parâmetros de Hanna. Pode-se observar que apesar das derivações serem obtidas por diferentes metodologias, os resultados foram similares e suficientemente satisfatórios. Para 0 caso convectivo, as melhores simulações de cada derivação apresentaram Erro Quadrático Médio Normalizado entre 0,04 e 0,05 quando comparados com os dados do experimento de Copenhagen.

Palavras-chave: modelo de dispersão, teoria de Taylor, escala de tempo lagrangeana.

\footnotetext{
1 Programa de Pós-Graduação em Meteorologia, Centro de Pesquisas e Previsões Meteorológicas, Universidade Federal de Pelotas, Av. Eng. Ildefonso Simões Lopes, 2751, Bairro Arco-Íris, 96060-290 Pelotas, RS, Brazil. Phone: +55(53) 3277-6690 / 3275-7328; Fax: +55(53) 3277-6722 - E-mails: andre.nunes@ufpel.edu.br; cjcampos@ufpel.edu.br

${ }^{2}$ Centro de Ciências Naturais e Exatas, Departamento de Física, Universidade Federal de Santa Maria, Cidade Universitária, Bairro Camobi, 97105-900 Santa Maria, RS, Brazil. Phone: +55(55) 3220-8616 - E-mail: gervasiodegrazia@gmail.com

$3^{3}$ Engenharia Ambiental e Energias Renováveis, Universidade Federal da Fronteira Sul, Av. Presidente Getúlio Vargas, 609N, Centro, 89812-000 Chapecó, SC, Brazil. Phone: +55(49) 2049-1401 - E-mail: davidson.moreira@gmail.com
} 


\section{INTRODUCTION}

The superficial concentration of pollutants is an important feature for estimating the environmental impact of punctual sources in lower atmosphere, that is, in the planetary boundary layer (PBL). Thereby, its study is generally a key purpose of the scientists that work in this scope. The diffusion-advection equation, that employs turbulent eddy diffusivity, was quite applied in simulating models of superficial mean concentration (Arya, 1999; Moreira et al., 2000; Vilhena et al., 2012). Basically, eddy diffusivities are coefficients that describe the kind of turbulence in the boundary layer and thus are function of surface heat flux. Therefore, eddy diffusivities (and other physical parameterizations) must be related to different phases diurnal cycle of PBL, as the convective phase (Degrazia et al., 1997 \& 2002; Nunes et al., 2003a), neutral phase (Blackadar, 1962; Garrat \& Hess, 2002; Nunes et al., 2003b), decaying phase (Sorbjan, 1997; Goulart et al., 2003; Silveira et al., 2005), stable phase (Degrazia \& Moraes 1992; Carvalho et al., 2009; Acevedo et al., 2012) and growing convection phase (Campos Velho 2003; Nunes et al., 2007, 2009, 2010).

The greater precise eddy diffusivity (employed on models) the better results of the simulations. Hence, in order to determining the behavior and accuracy of the coefficient to be employed in concentration field simulation, it is useful a comparison between the different turbulent eddy diffusivities. This fact motivated the accomplishment of this study. Specifically, the aim of this work is evaluate which coefficient formulation for convective conditions - basically Hostlag \& Moeng (1991), Degrazia et al. (1997) and Hanna (1982) - and for neutral conditions - Degrazia et al. (1997) and Hanna (1982) - is able to better simulate the pollutant concentration.

\section{METHODOLOGY}

The dispersion model used to simulate the pollutants concentration is presented below in two ways (Vilhena et al., 1998; Moreira et al., 1999):

$$
\begin{gathered}
\overline{c_{n}^{y}}(x, z)= \\
\sum_{j=1}^{8} A_{j} \frac{P_{j}}{x}\left(A_{n} e^{-\left(\sqrt{\frac{P_{j} U_{n}}{x K_{n}}}\right) z}+B_{n} e^{-\left(\sqrt{\frac{P_{j} U_{n}}{x K_{n}}}\right) z}\right)
\end{gathered}
$$

and

$$
\begin{gathered}
\overline{c_{n}^{y}}(x, z)= \\
\sum_{j=1}^{8} A_{j} \frac{P_{j}}{x}\left[A_{n} e^{-\left(\sqrt{\frac{P_{j} U_{n}}{x K_{n}}}\right) z}+B_{n} e^{-\left(\sqrt{\frac{P_{j} U_{n}}{x K_{n}}}\right) z}\right.
\end{gathered}
$$

$$
\begin{aligned}
& +\frac{1}{2} \frac{Q}{\sqrt{P_{j} K_{n} U_{n}} x}\left(e^{-\left(z-H_{s}\right)\left(\sqrt{\frac{P_{j} U_{n}}{x K_{N}}}\right)}\right. \\
& \left.\left.-e^{-\left(z-H_{s}\right)\left(\sqrt{\frac{P_{j} U_{n}}{x K_{N}}}\right)}\right)\right]
\end{aligned}
$$

where $\overline{c_{n}^{y}}(x, z)$ is the cross-wind integrated pollutants concentration, $A_{j}$ and $P_{j}$ are tabulated weights and roots of gaussian quadrature scheme (Stroud \& Secrest, 1966), $A_{n}$ and $B_{n}$ are integration constants which appear in the evaluation development, $x$ is the zonal distance, $U_{n}$ is the mean wind in each Convective Boundary Layer (CBL) sub layer, $z$ is the height above ground, $Q$ is the source emission rate, $H_{s}$ is the source height and $K_{n}$ is the convective eddy diffusivity in each sub layer Equation (1) is valid for CBL whitout source and Eq. (2) can be used to estimate the concentration field in $\mathrm{CBL}$ with pollutant source. Thus, for simulating the ground level cross-wind integrated concentration field, $H_{s}$ and $Q$ (given by experiment), $U$ vertical profile and $K$ are required. The wind profile employed in Eqs. (1) and (2) was parameterizated following the MoninObukhov Similarity Theory and the OML model (Bercowicz et al., 1986):

$$
U=\frac{u^{*}}{\kappa}\left[\ln \left(z / z_{0}\right)-\Psi_{m}(z / L)+\Psi_{m}\left(z_{0} / L\right)\right]
$$

if $z \leq z_{b}$ and

$$
U=U\left(z_{b}\right)
$$

if $z>z_{b}$, where $u_{*}$ is the friction velocity, $\kappa$ is the Von Karman constant $(\kappa=0.4), z_{0}$ is the aerodynamic roughness length, $L$ is the surface layer Monin-Obukhov length and $\Psi_{m}$ is the stability function (Paulsen, 1975):

$$
\begin{aligned}
\Psi_{m}= & 2 \ln \left[\frac{1+A}{2}\right]+\ln \left[\frac{1+A^{2}}{2}\right] \\
& -2 \tan ^{-1}(A)+\frac{\pi}{2}
\end{aligned}
$$

with

$$
A=(1-16 z / L)^{1 / 4}
$$

The Hostlag \& Moeng (hereafter, H-M) derivation take into account the entrainment flux, namely the flux that get down from entrainment zone (positive flux case) or that ascend into the entrainment zone (negative flux case). The H-M vertical eddy diffusivity $\mathrm{Kc}$ for any scalar is given by the follow equation (Hostlag \& Moneg, 1991):

$$
K_{c}=\frac{\left[1-\frac{z}{z_{i}}+R_{c} \frac{z}{z_{i}}\right] k_{b} k_{t}}{\left(1-\frac{z}{z_{i}}\right) k_{t}+R_{c}\left(\frac{z}{z_{i}}\right) k_{b}}
$$


where the parameterizated profiles $k_{b}$ and $k_{t}$, and $R_{c}$ can be expressed as:

$$
\begin{aligned}
\frac{k_{b}}{w_{*} z_{i}} & =\left(\frac{z}{z_{i}}\right)^{4 / 3}\left(1-\frac{z}{z_{i}}\right)^{2} \\
\frac{k_{t}}{w_{*} z_{i}} & =7\left(\frac{z}{z_{i}}\right)^{2}\left(1-\frac{z}{z_{i}}\right)^{3} \\
R_{c} & =\frac{\overline{w^{\prime} c_{1}^{\prime}}}{\overline{w^{\prime} c_{0}^{\prime}}}
\end{aligned}
$$

where $w_{*}$ is the convective velocity scale, $z_{i}$ is the convective boundary layer height and $R_{c}$ is the ratio between entrainment flux $\left(\overline{w^{\prime} c_{1}^{\prime}}\right)$ and surface flux $\left(\overline{w^{\prime} c_{0}^{\prime}}\right)$ for any scalar. Here, the analysis is made considering physically relevant values of $R_{c}$. For example, $R_{c}=0$ means that there is surface flux only; $R_{c}=0.5$ and 1.0 are typical values for situations involving entrainment fluxes; $R_{c}=\infty$ means exclusive occurrence of entrainment flux, what is not probable. Acevedo (2002) (personal communication) suggested the $K_{c}$ using negative $R_{c}$ simulation, by considering a negative entrainment flux situation, that is, a flow that enters in the entrainment zone. Thus, five values of $R_{c}$ were tested: $1.0 ; 0.5 ; 0.0 ;-0.5$ and -1.0 .

The vertical eddy diffusivities for convective boundary layer suggested by Degrazia et al. (Degrazia et al. 1997) were constructed from the Taylor's Statistical Diffusion Theory (Taylor, 1921) and by employment of turbulent kinetic energy spectra. Following the formulation of vertical velocity variance from Sorbjan (1989), the coefficient assumes the form below:

$$
\begin{gathered}
\frac{K_{z}}{w_{*} z_{i}}=0.22\left(\frac{z}{z_{i}}\right)^{1 / 3}\left(1-\frac{z}{z_{i}}\right)^{1 / 3} \\
{\left[1-\exp \left(-4 \frac{z}{z_{i}}\right)-0.003 \exp \left(8 \frac{z}{z_{i}}\right)\right]}
\end{gathered}
$$

and according to the velocity variance by Degrazia et al. (1997), the coefficient assumes the following form:

$$
\begin{gathered}
\frac{K_{z}}{w_{*} z_{i}}=0.15 \Psi^{1 / 3} \\
{\left[1-\exp \left(-4 \frac{z}{z_{i}}\right)-0.003 \exp \left(8 \frac{z}{z_{i}}\right)\right]^{4 / 3}}
\end{gathered}
$$

The function $\Psi$ in Eq. (12) is evaluated from two different ways: 1st following the approach suggested by (Hojstrup, 1982):

$$
\Psi^{1 / 3}=\left[\left(1-\frac{z}{z_{i}}\right)^{2}\left(-\frac{z_{i}}{L} \frac{z}{z_{i}}\right)^{2 / 3}+0.75\right]^{1 / 2}
$$

2nd following Degrazia (1998):

$$
\Psi^{1 / 3}=0.97
$$

The derivation gotten through the parameters of Hanna (Hanna, 1982) is based on the Taylor's Statistical Diffusion Theory, in accordance with Batchelor (1949), and therefore is presented in the following form:

$$
K_{z}=\sigma_{2}^{2} T_{w}
$$

where $\sigma_{w}^{2}$ is the variance of turbulent vertical velocity and $T_{w}$ is the vertical decorrelation timescale. According Hanna (1982), the following vertical profiles of $\sigma_{w}^{2}$ and $T_{w}$ for a convective boundary layer are proposed:

$$
\frac{\sigma_{w}}{w_{*}}=\min \left[0.96\left(3 \frac{z}{z_{i}}-\frac{L}{z_{i}}\right)^{1 / 3}, 0.763\left(\frac{z}{z_{i}}\right)^{0.175}\right]
$$

For $0 \leq \frac{z}{z_{i}} \leq 0.4$,

$$
\frac{\sigma_{w}}{w_{*}}=0.722\left(1-\frac{z}{z_{i}}\right)^{0.207}
$$

For $0.4<\frac{z}{z_{i}} \leq 1$, and

$$
T_{L}^{w}=0.59 \frac{Z}{\sigma_{w}}
$$

For $\frac{z}{z_{i}} \leq 0.1$, and

$$
T_{L}^{w}=0.15 \frac{Z_{i}}{\sigma_{w}}\left[1-\exp \left(-5 \frac{Z}{Z_{i}}\right)\right]
$$

For $\frac{z}{z_{i}}>0.1$.

Firstly, the eddy diffusivity was formulated for two regions of the CBL: one comprehending the $40 \%$ lowest of the CBL and another comprehending the $60 \%$ remaining. The velocity variances are obtained by raising Eqs. (16) and (17) to the second power. Substituting the variances and Eq. (19) in Eq. (15), the following vertical profiles of $\mathrm{Kz}$ can be gotten:

$$
\frac{K_{z}}{w_{*} z_{i}}=0.114\left(\frac{z}{z_{i}}\right)^{0.175}\left(1-\exp \left(-\frac{5 z}{z_{i}}\right)\right)
$$

For $0 \leq \frac{z}{z_{i}} \leq 0.4$ and

$$
\frac{K_{z}}{w_{*} z_{i}}=0.108\left(1-\frac{z}{z_{i}}\right)^{0.207}\left(1-\exp \left(-\frac{5 z}{z_{i}}\right)\right)
$$

For $0.4<\frac{z}{z_{i}} \leq 1$.

In order to elaborate a more accurate model, we can also derivate the eddy diffusivity for three $\mathrm{CBL}$ regions: the first region 
comprehending $10 \%$ of the CBL (surface layer, approximately), the second comprehending the region from 10 up to $40 \%$ of the $\mathrm{CBL}$, and the third comprehending the $60 \%$ remaining. Since eddy diffusivity is obtained by the product between the velocity variances and the Lagrangian timescale, joining Eqs. (16) and (18), (16) and (19), and (17) and (19) we get the following eddy diffusivities:

$$
\frac{K_{z}}{w_{*} Z_{i}}=0.45\left(\frac{z}{z_{i}}\right)^{1.175}
$$

For $\frac{z}{z_{i}} \leq 0.1$,

$$
\frac{K_{z}}{w_{*} z_{i}}=0.114\left(\frac{z}{z_{i}}\right)^{0.175}\left(1-\exp \left(-\frac{5 z}{z_{i}}\right)\right)
$$

For $0.1 \leq \frac{z}{z_{i}} \leq 0.4$, and

$$
\frac{K_{z}}{w_{*} z_{i}}=0.108\left(1-\frac{z}{z_{i}}\right)^{0.207}\left(1-\exp \left(-\frac{5 z}{z_{i}}\right)\right)
$$

For $0.4<\frac{z}{z_{i}} \leq 0.1$.

For a boundary layer under neutral conditions, when the turbulence occurs only due mechanical effects, Degrazia et al. (2000) proposed a vertical eddy diffusivity constructed from Taylor's Theory (Taylor, 1921) and by employment of turbulent kinetic energy spectra for a shear-dominated planetary boundary layer. In this way, the neutral or stable vertical eddy diffusivity is shown below:

$$
K_{w}^{n+s}=\frac{0.4(1+3.7 z / \Lambda)^{1 / 3} u * z}{\left[1+15 f_{c} z /\left(u_{*}\right)_{0}+3.7 \frac{z}{\Lambda}\right]^{4 / 3}}
$$

where $f_{c}$ is the Coriolis parameter and $\left(u_{*}\right)_{0}$ is the surface friction velocity. To achieve a coefficient only for neutral conditions, it is necessary to obtain the limit for $L \rightarrow \infty$, knowing that the local Monin-Obukhov length is (Nieuwstadt, 1984):

$$
\Lambda=L(1-z / h)^{5 / 4}
$$

where $h$ is the shear-dominated boundary layer height. Therefore, the neutral eddy diffusivity is given by:

$$
K_{w}^{n}=\frac{0.4(1-z / h)^{0.85}\left(u_{*}\right)_{0} z}{\left[1+15 f_{c} z /\left(u_{*}\right)_{0}\right]^{4 / 3}}
$$

Similar to convective case, that is, by means of Taylor's Theory (Taylor, 1921; Batchelor, 1949), neutral eddy diffusivities can be obtained from neutral parameters from Hanna (Hanna, 1982).
However, here there is just one velocity variance equation for entire layer:

$$
\left(\frac{\sigma_{w}}{u_{*}}\right)^{2}=\left[1.3 \exp \left(-2 \frac{2 f_{c} z}{u_{*}}\right)\right]^{2}
$$

and in the same way, one equation for the Lagrangian timescale only:

$$
T_{L}=\frac{0.5 z / \sigma}{1+15 f_{c} z / u_{*}}
$$

Thus, we get the neutral eddy diffusivity:

$$
K_{w}^{n}=0.65 \frac{\left[\exp \left(-\frac{-2 f_{c} z}{u_{*}}\right)\right] z u_{*}}{\left(1+15 \frac{f_{c} z}{u_{*}}\right)}
$$

\section{DATASET EXPERIMENTS}

The concentration data obtained by theoretical models presented here were confronted against observed data from two datasets experiments: Copenhagen and Praire Grass. The Copenhagen experiment (Gryning \& Lyck, 2002) was performed between 1978 and 1979 and it is considered one of the most important in the study of pollutant dispersion. The tracer used in the experiment was the sulfur hexafluoride (SF6), released from a 115 meters tower. The 2 to 3 meters collectors were placed in arches distant 2 to $6 \mathrm{~km}$ from the source, as shown in Figure 1 .

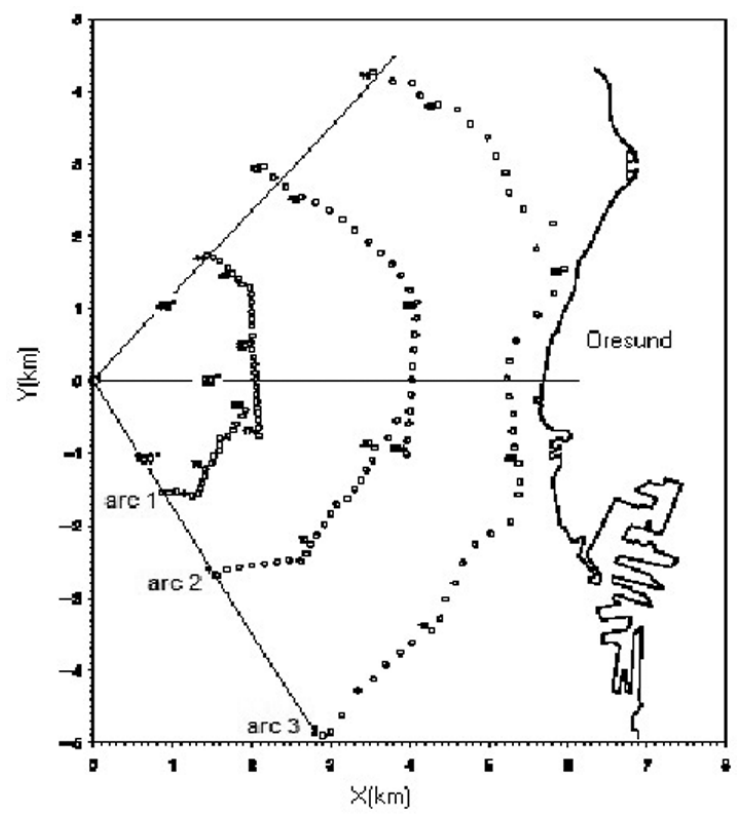

Figure 1 - The Copenhagen Experiment. The $x$-axis is pointing towards East, the $y$-axis towards North and the sampling unit positions are indicated by circles. The tracer was released at 115 meters height at the position $(x, y)=(0,0)$ (Gryning \& Lyck, 2002) 
The concentration was measured in three consecutive 20minutes intervals, for a total time of 1 hour sample. The place was mainly residential, with a mean roughness length of $0.6 \mathrm{~m}$. A total of ten days of measurements were performed between 1978 and 1979.

The Praire Grass low source dispersion experiment (Barad \& Haugen, 1959) was performed in O'Neill, Nebraska (USA), in 1956. The sulfur dioxide (S02) tracer was released at 0.5 meters height and sampled in concentric arcs at distances of 50 , 100, 200, 400 and 800 meters. For each distance, the distribution concentration was measured along the arcs. The site was fairly flat, with a roughness length of $0.6 \mathrm{~cm}$.

\section{RESULTS}

The vertical profiles of Hostlag and Moeng convective eddy diffusivities - Eq. (7) - are presented in Figure 2. As mentioned before, five values of $R_{c}$ will be tested: $1.0 ; 0.5 ; 0.0 ;-0.5$ and -1.0 .

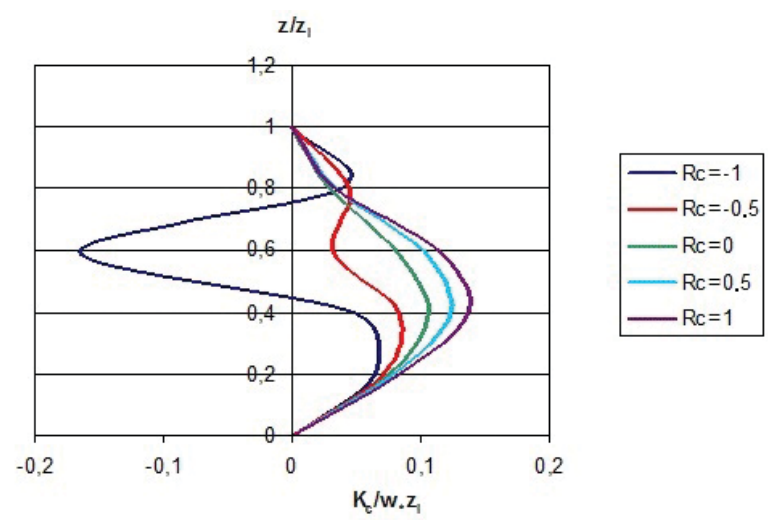

Figure 2 - Vertical profiles of H-M normalized convective eddy diffusivities for different Rc values. In purple the derivation using $R_{c}=1$, in light blue $R_{c}=0.5$, in green $R_{c}=0$, in red $R_{c}=-0.5$ and in dark blue $R_{c}=-1$.

We observe that the coefficients employing $R_{c} \geq 0$ presented an expected profile, with zero values in surface and on CBL top and maximum values in about the middle of the layer. On the other hand, coefficients that used a negative $R_{c}$ presented a decreasing values in about $0.6 z_{i}$. To find out which of $\mathrm{H}-\mathrm{M}$ coefficients obtained better performance, the results of the simulations using these eddy diffusivities were compared with the Copenhagen experiment dataset. Table 1 shows the results of simulations employing different values of $R_{c}$, when submitted to the statistical indices (Hanna, 1989).

Where NMSE is the Normalized Mean Squared Error, which optimum value is zero, as well as FB (fractional bias) and SFB (standard fractional bias); $\mathrm{R}$ is the correlation coefficient, which optimum value is 1 , as well as FA2 (fraction of data). We noted that the only simulation that did not achieve satisfatory results was that which used $K_{c}$ with $R_{c}=-1$. This value of $R_{c}$ represents a boundary layer with a negative entrainment flux (ascending toward entrainment zone) with the same intensity of the ascending surface flux. In other words, in this case we are considering that the whole flux that ascends from the surface enters in the entrainment zone, what is unlikely for a scalar flux. The improbable behavior of this coefficient can be verified in its vertical profile, when $K_{c}$ presents negative values (what it does have not physical value) for $z=0.6 z_{i}$. On the other hand, the other coefficients presented similar and satisfactory values, where that one which employed $R_{c}=-0.5$ obtained the better results. This means we must consider the ascending entrainment flux and with magnitude equal the half of the surface flux, that is, there is a decreasing (in approximately $50 \%$ ), and not an interruption, of the surface flux when arrives in the entrainment zone.

Table 1 - Accuracy of simulations employing H-M convective eddy diffusivity in accordance with Copenhagen experiment.

\begin{tabular}{|c|c|c|c|c|c|}
\hline $\mathrm{K}_{\mathrm{c}}(\mathrm{H}-\mathrm{M})$ & $\mathrm{NMSE}$ & $\mathrm{R}$ & $\mathrm{FA} 2$ & $\mathrm{FB}$ & $\mathrm{SFB}$ \\
\hline$R_{c}=-1.0$ & 0.32 & 0.734 & 0.870 & -0.201 & -0.460 \\
$R_{c}=-0.5$ & 0.04 & 0.922 & 1.000 & 0.022 & 0.055 \\
$R_{c}=0.0$ & 0.05 & 0.926 & 1.000 & 0.067 & 0.120 \\
$R_{c}=0.5$ & 0.05 & 0.929 & 1.000 & 0.093 & 0.151 \\
$R_{c}=1.0$ & 0.06 & 0.930 & 1.000 & 0.112 & 0.170 \\
\hline
\end{tabular}

Figure 3 presents the vertical profiles of Degrazia et al. convective eddy diffusivities. The comparison is made between the Eqs. (11), (12) with $\Psi$ from (13), and (12) with $\Psi$ from (14).

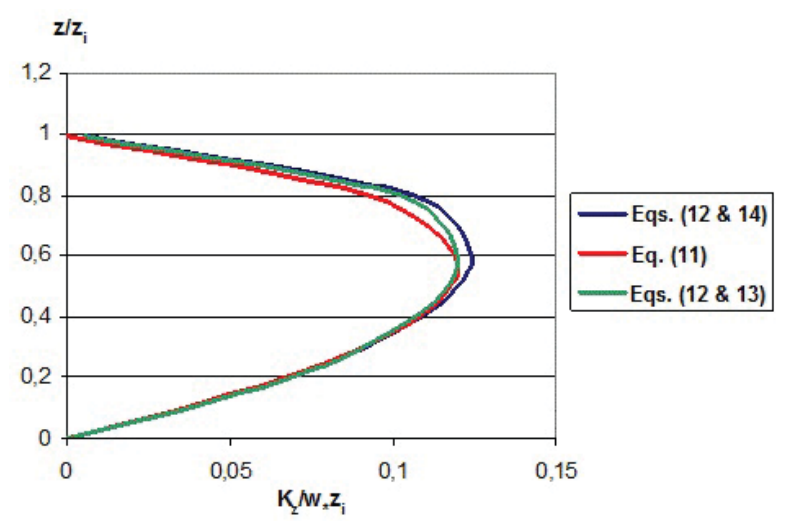

Figure 3 - Vertical profiles of normalized convective eddy diffusivities for different derivations from Degrazia et al. formulation. In blue, the derivation using Eqs. 12 and 14, in red using Eq. 11 and in green using Eqs. 12 and 13. 
A similar behavior of the profiles is observed. The distinction between them is better observed when the simulations results are compared with the Copenhagen data and submitted to statistical indices, as shown in Table 2.

Table 2 - Accuracy of simulations employing Degrazia et al. convective eddy diffusivity in accordance with Copenhagen experiment.

\begin{tabular}{|c|c|c|c|c|c|}
\hline $\mathrm{K}_{\mathrm{z}}$ - Degrazia & NMSE & $\mathrm{R}$ & $\mathrm{FA} 2$ & $\mathrm{FB}$ & $\mathrm{SFB}$ \\
\hline Eq. (11) & 0.04 & 0.923 & 1.000 & 0.017 & 0.131 \\
Eqs. (12) \& (13) & 0.05 & 0.923 & 1.000 & 0.039 & 0.136 \\
Eqs. (12) \& (14) & 0.04 & 0.922 & 1.000 & 0.023 & 0.128 \\
\hline
\end{tabular}

Here, we verified that despite the difference between these derivations (for example, the derivation with $\Psi$ was determined more analytically), the coefficients presented quite similar and satisfactory results. The coefficient that used $\Psi$ from Hojstrup - Eq. (13) - presented a lightly bigger error, and the difference between the results from others Degrazia simulations is really negligible. Thus, we considered the coefficient from Eqs. (12) and (14) as the better results from Degrazia derivations.

In Figure 4 is presented the vertical profiles of the two derivations obtained by employing the parameters of Hanna: 2 and 3 layers (CBL regions) convective eddy diffusivities.
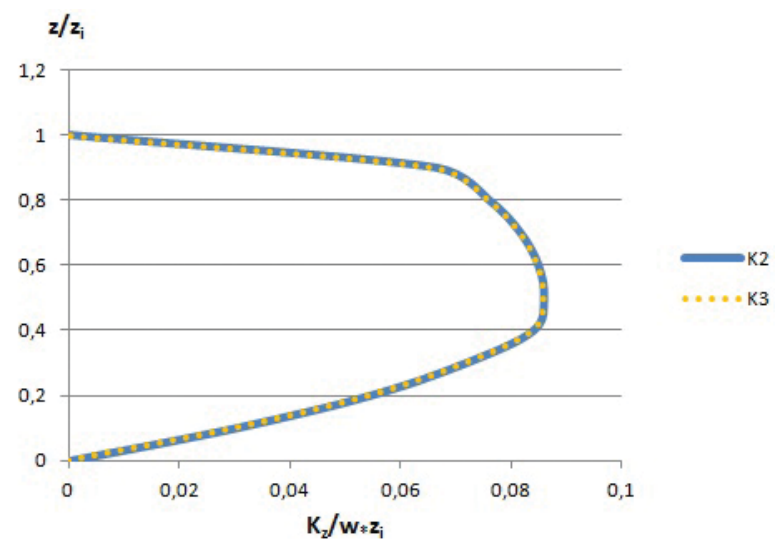

Figure 4 - Vertical profiles of normalized convective eddy diffusivities based on Hanna parameters. K2 (blue solid line) is the 2-layers coefficient and K3 (dotted orange line) is the 3-layers coefficient.

Due to the similarity of derivations the profiles are overlapped. The 3-layers coefficient differs from 2-layers because the former has an equation for the first 10\% (from 0 to $0.1 z_{i}$ ) of the CBL. Thus, an enlargement of the picture in this region (approximately the superficial layer) is shown in Figure 5. Table 3 shows the accuracy of the models that employ the coefficients based on Hanna parameters, in comparison with the Copenhagen experiment data.

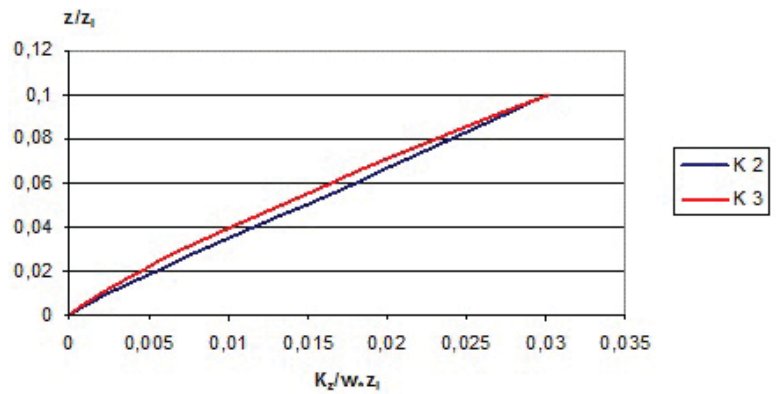

Figure 5 - As Figure 4, but only for Superficial Layer. K2 in blue and K3 in red.

Table 3 - Accuracy of simulations employing the based on Hanna parameters convective eddy diffusivity in accordance with Copenhagen experiment.

\begin{tabular}{|c|c|c|c|c|c|}
\hline$K_{z}-$ Hanna & NMSE & $R$ & $F A 2$ & $F B$ & SFB \\
\hline 2-layers & 0.05 & 0.917 & 1.000 & -0.039 & 0.061 \\
3-layers & 0.05 & 0.916 & 1.000 & -0.054 & 0.067 \\
\hline
\end{tabular}

The results are satisfactory and without significant difference between them, what was expected due to similarity of the equations. In the comparison with the Copenhagen experiment data, both models have obtained quite similar results. Therefore, for simplicity, the 2-layers coefficient was chosen as that one of better performance.

In this work, all simulations were confronted against Copenhagen dataset. However, just as observation, it is interesting to check the comparison between these simulations from parameters of Hanna and the data of Praire Grass experiment, since this is a low source experiment and the major difference between these two simulations is found in low levels of the CBL. In such confrontation, as expected, the simulation that used the 3-layers coefficient obtained a lightly better result than 2-layers coefficient.

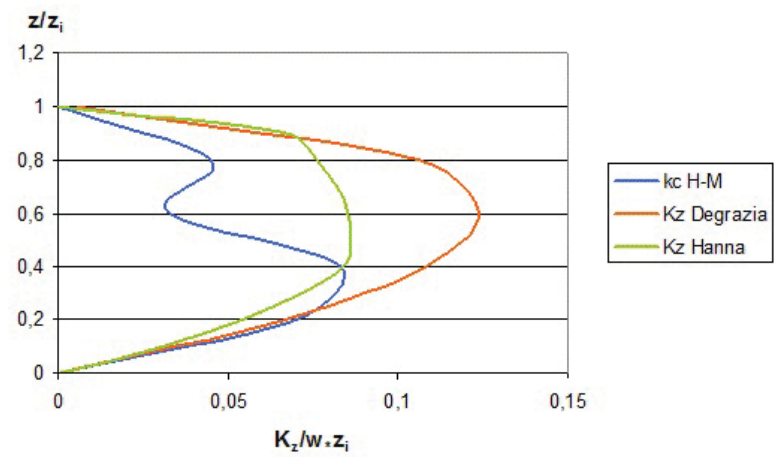

Figure 6 - Vertical profiles of the best normalized convective eddy diffusivity of each derivation, being H-M (blue), Degrazia et al. (orange) and from Hanna parameters (green).

Next, it is shown a comparison between the convective eddy diffusivities that presented better performance from each authorship. In Figure 6, the vertical profiles of the convective eddy 
diffusivities that presented better performance are shown: from Hostlag \& Moneg, $K_{c}$ using $R_{c}=-0.5$; from Degrazia et al., $K_{z}$ from Eqs. (11) and (13); and from the Hanna parameters, the 2-layers $K_{z}$. The simulated data were collated against the Copenhagen experiment data. The only observed difference is found between the behavior of the Hostlag and Moeng profile and the other derivations. However, all the coefficients differ in magnitude.

The comparison between simulations and the observed data is shown in Figure 7, where satisfactory results in the comparison with the Copenhagen dataset (set of 23 experiments or samples) were observed, and a little difference between the simulations was also noticed. More details of the model precision using the different coefficients are presented in Table 4, through the statistical indices.

Table 4 - Comparison between the simulations and the Copenhagen dataset. $\mathrm{H}-\mathrm{M}$ is the simulation employing $R_{c}=-0.5$ of $\mathrm{H}-\mathrm{M}$ derivation, Degrazia is the simulation employing Eqs. (12) and (14) and Hanna is the simulation employing the 2-layer derivation based on Hanna parameters.

\begin{tabular}{|c|c|c|c|c|c|}
\hline Best derivations & NMSE & R & FA2 & FB & SFB \\
\hline H-M & 0.04 & 0.922 & 1.000 & 0.022 & 0.055 \\
Degrazia & 0.04 & 0.922 & 1.000 & 0.023 & 0.128 \\
Hanna & 0.05 & 0.917 & 1.000 & -0.039 & 0.061 \\
\hline
\end{tabular}

Despite the models have used coefficients determined by different authors and methods, we can observe that the results are quite similar and the simulations reproduce the observed superficial concentrations in a sufficiently satisfactory way. Hence, this work highlights that anyone of these derivations can be used in models to simulate the concentration of pollutants in the Convective Boundary Layer. However, the better performance model is one that employs the H-M eddy diffusivity considering the existence of an ascending flux in the entrainment zone with magnitude equal the half of the magnitude of surface ascending flux.

The simulations considering almost neutral conditions were compared with the data from the less convective (tending to neutrality) cases of the Copenhagen experiment. To define the less convective cases the stability factor $z_{i} /|L| \leq 7$ was adopted. Such almost neutral situation was verified in 4 days of the experiment, counting 9 samples. The comparison between the simulations and the less convectives experiments of Copenhagen is shown in Figure 8.

In this case, presumably, the statistical indices would indicate that the best results are that of coefficient derived from Hanna parameters. However, due to low number of experiments (less than 10), the employment of such indices could be not convenient. The direct comparison between the concentration data (Fig. 8) indicates a smoothing overestimate of the results in both simulations, what can be noticed in Table 5. Even so, the results can be considered as satisfactory.

Table $\mathbf{5}$ - Comparison between concentration data from neutral derivations, Degrazia et al. and that from Hanna parameters, and the observed data from the less convective samples from Copenhagen experiment.

\begin{tabular}{|c|c|c|c|}
\hline $\begin{array}{c}\text { Almost neutral } \\
\text { samples }\end{array}$ & $\begin{array}{c}\text { Observed } \\
\text { concentration }\end{array}$ & $\begin{array}{c}\text { Degrazia } \\
\text { et al. }\end{array}$ & $\begin{array}{c}\text { Hanna } \\
\text { parameters }\end{array}$ \\
\hline 1 & 5.38 & 5.26 & 5.17 \\
2 & 2.95 & 4.96 & 4.03 \\
3 & 11.66 & 13.17 & 10.45 \\
4 & 6.72 & 8.02 & 8.49 \\
5 & 5.84 & 8.53 & 7.14 \\
6 & 4.97 & 7.81 & 5.94 \\
7 & 3.96 & 3.35 & 3.34 \\
8 & 2.22 & 3.24 & 2.56 \\
9 & 1.83 & 2.88 & 2.09 \\
\hline
\end{tabular}

In accordance with Table 5, with exception of experiment 3, both simulations underestimate or overestimate in the same occasions. It is verified that the results do not differ significantly between them.

\section{CONCLUSIONS}

In the present study, the eddy diffusivities behavior (vertical profiles) and its skills in simulations of superficial concentration of pollutants released by continuous punctual sources were analyzed. Different derivations of convective and neutral eddy diffusivities were tested by the employment of Eulerian dispersion model, whose results were confronted against the data of the Copenhagen experiment. In total, 12 models were simulated. First, the behaviors of derivations of each author were compared between them. To evaluate the convective eddy diffusivities of Hostlag and Moeng, five simulations are made (for five different values of $R_{c}$ ). We observed a good and very similar behavior for values of $R_{c}$ between -0.5 and 1.0 , and a unlikely behavior for $R_{c}=-1.0$. Three simulations using Degrazia derivations of convective eddy diffusivity were made, being all of good and very similar results, with small advantage for the model that employed the derivation using a constant dissipation rate (0.97). Four simulations for convective eddy diffusivities based on the parameters of Hanna were performed. These simulations have used different equations for different regions (layers) of the CBL. Thereby, the 3-layers and 2-layers models were evaluated. The simulations have good agreement when compared with Copenhagen 


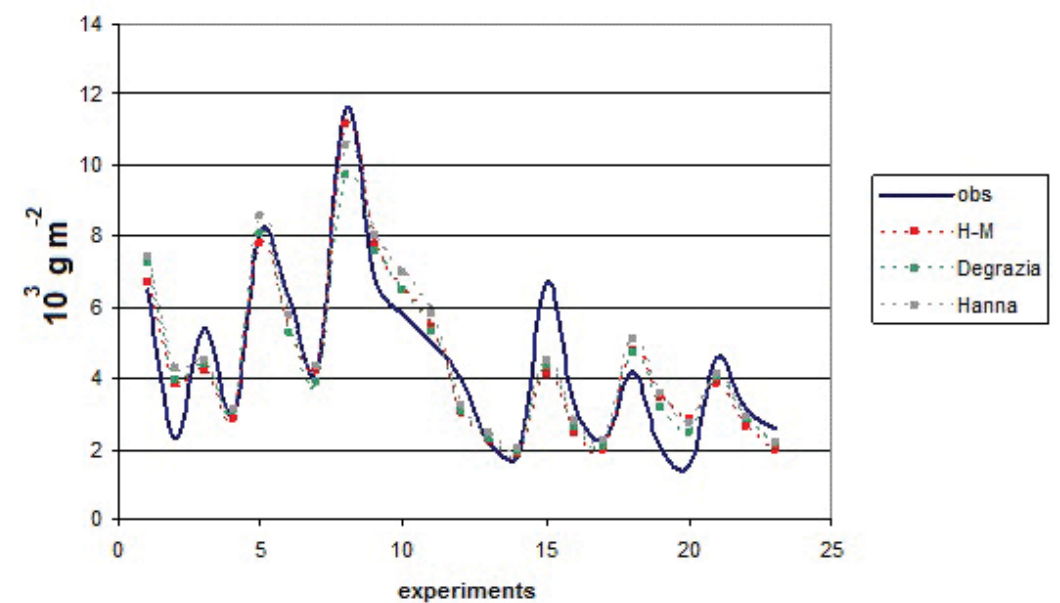

Figure 7 - Comparison between simulated concentration data (dotted lines) and observed data from Copenhagen experiment (concentration of SF6, blue line), where the orange dots is the H-M derivation, in green dots the Degrazia et al. derivation and in gray dots the derivation based on Hanna parameters.

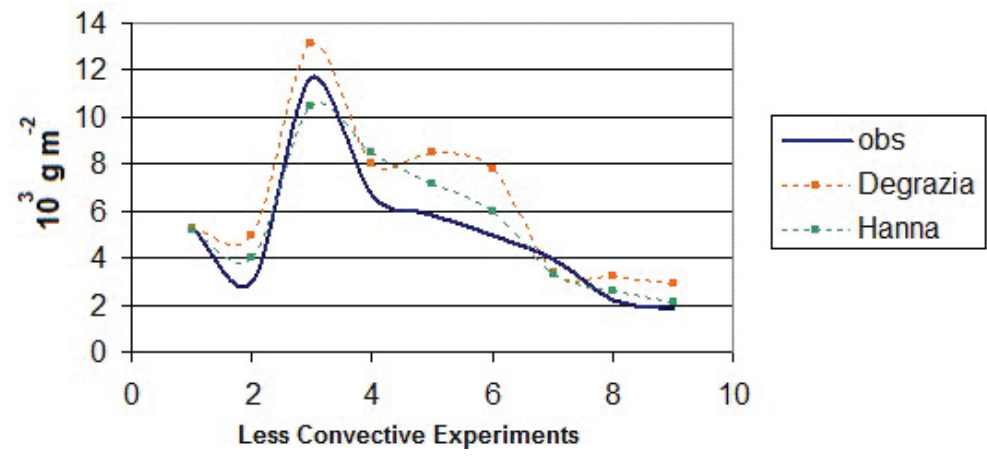

Figure 8 - Comparison between the simulations employing Degrazia et al. neutral derivation (orange dashed line), neutral derivation from Hanna parameters (green dashed line) and the less convective samples from Copenhagen experiment (blue line).

data but, since the difference between them was worthless, the results were also compared with Praire Grass dataset (low source experiment). Thus, we verified that the 3-layers model presented better results in this case.

The simulations using the better performance convective eddy diffusivities from each author were compared between them, and we can point out that despite the derivations employ different methodologies, the results were satisfactory and similar. Therefore, it is possible to affirm that the 3 different derivations of convective eddy diffusivities generated good results and can be used to simulate the pollutants superficial concentration field.

For a boundary layer in near neutral conditions, two simulations were performed: one using a Degrazia derivation and another based on parameters of Hanna. Most of the simulated results for both models overestimated the observed data but, however, both derivations reproduced the superficial concentrations in an adequate way.

Finally, by the employment of statistical indices, it can be concluded that the eddy diffusivities argued in this work can be used in operational models that evaluate the air quality and pollutants superficial concentration field.

\section{REFERENCES}

ACEVEDO OC, COSTA FD \& DEGRAZIA GA. 2012. The coupling state of an idealized stable boundary layer. Boundary-Layer Meteorol, 145: 211-228.

ARYA S. 1999. Air Pollution Meteorology and Dispersion, Oxford University Press, New York. 320 pp.

BARAD ML \& HAUGEN DA. 1959. A preliminary evaluation of Sutton's 
hypothesis for diffusion from a continuous point source. J. Meteor. Sci., 16: 12-20.

BATCHELOR GK. 1949. Diffusion in a field of homogeneous turbulence I: Eulerian analysis. Aust. J. Sci., 2: 437-450.

BERCOWICZ RR, OLESEN HR \& TORP U. 1986. The Danish Gaussian air pollution model (OML): Description, test and sensivity analysis in view of regulatory applications. In: WISPELEARE C, SCHIERMEIRIER FA, GILLANI NV (Eds.). Air Pollution modeling and its application. Plenum Publishing Corporation, p. 453-480.

BLACKADAR AK. 1962. The vertical distribution of wind and turbulent exchange in a neutral atmosphere. J. Geophys. Res., 67: 3095-3102.

CAMPOS VELHO HF. 2003. A preliminary model for growing of the convective boundary layer. Ciência e Natura, vol. Especial: 99-102.

CARVALHO JC, RIZZA U, LOVATO R, DEGRAZIA GA, MARQUES FILHO EP \& CAMPOS CRJ. 2009. Estimation of the Kolmogorov constant by large-eddy simulation in the stable PBL. Physica. A, 388: 1500-1508.

DEGRAZIA GA \& MORAES OLL. 1992. A model for eddy diffusivity in a stable boundary layer. Boundary-Layer Meteorol., 58: 205-214.

DEGRAZIA GA, RIZZA U, MANGIA C \& TIRIBASSI T. 1997. Validation of a new turbulent parameterization for dispersion models in convective conditions. Boundary-Layer Meteorol., 85: 243-254.

DEGRAZIA GA. 1998. Modelling dispersion from elevated sources in a planetary boundary layer dominated by moderate convection. II Nuovo Cimento, 21C: 345-353.

DEGRAZIA GA, ANFOSSID, CARVALHOJC, MANGIA C, TIRABASSI T \& CAMPOS VELHO HF. 2000. Turbulence parametrization for PBL dispersion models in all stability conditions. Atmos. Environ., 34: 3575-3583.

DEGRAZIA GA, MOREIRA DM, NUNES AB, CAMPOS CRJ, PROCHNOW AR \& FONSECA FA. 2002. Comparação entre coeficientes de difusão derivados do espectro de energía turbulenta e coeficientes de difusão que dependem da razão entre os fluxos de entranhamento e os de superfície. Ciência e Natura, vol. Especial: 9-19.

GARRATT JR \& HESS GD. 2002. Neutrally stratified boundary layer. In: Encyclopedia of Atmospheric Sciences. Academic Press. Elsevier, 262-271.

GOULART A, DEGRAZIA GA, RIZZA U \& ANFOSSID. 2003. A theoretical model for the study of convective turbulence decay and comparison with large-eddy simulation data. Boundary-Layer Meteorol., 107: 143-155.

GRYNING SE \& LYCK E. 2002. The Copenhagen Tracer Experiments: Reporting of Measurements. Riso National Laboratory, Roskilde, 75 pp.

HANNA SR. 1982. Applications in air pollution modeling. In: Atmospheric Turbulence and Air Pollution Modeling, FTM NIEUWSTADT \& HV DOP (Eds.). D. Reidel Publishing, 275-310.
HANNA SR. 1989. Confidence limit for air quality models as estimated by bootstrap and jacknife resampling methods. Atmos. Environ., 23: 1385-1395.

HOJSTRUP J. 1982. Velocity spectra in the unstable boundary layer. J. Atmos. Sci., 33: 2152-2169.

HOLTSLAG AAM \& MOENG CH. 1991. Eddy diffusivity and countergradient transport in the convective boundary layer. J. Atmos. Sci., 48: 1690-1698.

MOREIRA DM, DEGRAZIA GA \& VILHENA MT. 1999. Dispersion from low sources in a convective boundary layer: An analytical model. ॥ Nuovo Cimento, 22C: 685-691.

MOREIRA DM, DEGRAZIA GA, VILHENA MT, RIZZA U \& MANGIA C. 2000. Modelo Euleriano semi-analítico para a dispersão de contaminantes na Camada Limite Planetária. In: Tópicos Especiais em Física da Camada Limite Planetária e Modelagem de Processos de Dispersão. Pelotas: UFPel, p. 83-93.

NIEUWSTADT FTM. 1984. The Turbulent Structure of the Stable, Nocturnal Boundary Layer. J. Atmos. Sci., 41: 2202-2216.

NUNES AB, DEGRAZIA GA, CAMPOS CRJ, MOREIRA DM \& FONSECA JF. 2003a. Comparação entre coeficientes de difusão turbulentos válidos para uma camada limite convectiva. Ciência e Natura, v. esp.: 65-68.

NUNES AB, DEGRAZIA GA, CAMPOS CRJ, MOREIRA DM \& FONSECA JF. 2003b. Comparação entre coeficientes de difusão turbulentos válidos para uma camada limite neutra. Ciência e Natura, v. esp.: 61-64.

NUNES AB, CAMPOS VELHO HF \& SATYAMURTY P. 2007. Spatial scale of energy-containing eddies during the morning transition by theoretical modeling. Ciência e Natura. V Especial Micrometeorologia: 345-348.

NUNES AB, CAMPOS VELHO HF, SATYAMURTY P, DEGRAZIA GA, GOULART A \& RIZZA U. 2009. Convective boundary layer growth: analytical and numerical approaches. Ciência e Natura, 31: 25-28.

NUNES AB, CAMPOS VELHO HF, SATYAMURTY P, DEGRAZIA GA, GOULART A \& RIZZA U. 2010. Morning boundary-layer turbulent kinetic energy by theoretical models. Boundary-Layer Meteorol., 134: 23-39.

PAULSEN CA. 1975. The mathematical representation of wind and temperature profiles in the unstable atmospheric surface layer. J. Appl. Met., 9: 857-861.

SILVEIRA CP, CAMPOS CRJ, MOREIRA DM \& DEGRAZIA GA. 2005. Influência do decaimento da turbulência convectiva no cálculo da concentração de contaminantes próximo à superfície. Rev. Bras. Meteorol., 20: 75-82.

SORBJAN Z. 1989. Structure of the Atmospheric Boundary Layer. Prentice Hall, NJ, 317 pp. 
SORBJAN Z. 1997. Decay of convective turbulence revisited. BoundaryLayer Meteorol., 82: 501-515.

STROUD AH \& SECREST D. 1966. Gaussian Quadrature Formulas. New Jersey: Prentice Hall, 374 pp.

TAYLOR GI. 1921. Diffusion by continuous movements. Procedings London Mathematical Society. Series 2, 20: 196-211.
VILHENA MT, RIZZA U, DEGRAZIA GA, MANGIA C, MOREIRA DM \& TIRIBASSI T. 1998. An Analytical Air Pollution Model: Development and Evaluation. Contr. Atmos. Phys., 71: 315-320.

VILHENA MT, BUSKE D, DEGRAZIA GA \& QUADROS RS. 2012. An analytical model with temporal variable eddy diffusivity applied to contaminant dispersion in the atmospheric boundary layer. Physica A, 391: $2576-2584$

Recebido em 19 novembro, 2012 / Aceito em 17 maio, 2013

Received on November 19, 2012 / Accepted on May 17, 2013

\section{NOTES ABOUT THE AUTHORS}

André Becker Nunes. B.S. in Meteorology (2000) at Universidade Federal de Pelotas (UFPel). M.Sc. in Meteorology (2002), thesis on Planetary Boundary Layer Physics, at UFPel. Doctorate in Meteorology (2008), thesis on Micrometeorological Modeling, at Instituto Nacional de Pesquisas Espaciais (INPE). Participation in the Climate Change Group of CCST-INPE, between 2008 and 2009. Professor of the Faculty of Meteorology at UFPel since 2009, acting in graduate and undergraduate courses. M.Sc. and undergraduate advisor in Climatology, Climate Change, Synoptic Meteorology, Agrometeorology and Micrometeorology. Head of the Department of Meteorology of UFPel (2010-2012, 2012-2014).

Gervásio Annes Degrazia. B.S. in Physics (1979) at Universidade Federal do Rio Grande do Sul (UFRGS). M.Sc. in Physics (1984) at UFRGS. Doctorate in Natural Sciences (1988) at Karlsruher Institut für Technologie (Germany). Post Doctorate in Micrometeorology (1998) at Consiglio Nazionale delle Riecerche (Italy). Professor of Physics Department of Centro de Ciências Naturais e Exatas (CCNE) at Universidade Federal de Santa Maria (UFSM). Research experience in Geosciences, with emphasis in Meteorology. Doctorate advisor in Atmospheric Turbulence and Micrometeorological Modeling. Books published/organized about Micrometeorology. Scholarship in Research Productivity $1 \mathrm{~A}$ at CNPq.

Cláudia Rejane Jacondino de Campos B.S. in Meteorology (1988) at Universidade Federal de Pelotas (UFPel). M.Sc. in Agronomy (Agricultural Meteorology) (1990) at Universidade Federal de Viçosa (UFV). Doctorate in Atmospheric Physics (1996) at Université Toulouse III Paul Sabatier (France). Research experience in Geosciences, with emphasis in Convective Mesoscale Systems and Mesoscale Modeling. Professor of the Faculty of Meteorology at UFPel since 1991, acting in graduate and undergraduate courses. Doctorate, M.Sc. and undergraduate advisor in Agrometeorology, Extreme Events, Mesoscale Meteorology and Micrometeorology. Book published about Micrometeorology (2004). Scholarship in Research Productivity 2 at CNPq.

Davidson Martins Moreira B.S. in Physics (1992) at Universidade Federal de Santa Maria (UFSM). M.Sc. in Physics (1996) at UFSM. Doctorate in Mechanical Engineering (2000) at Universidade Federal do Rio Grande do Sul (UFRGS). Professor of the Environmental Engineering at Universidade Federal da Fronteira Sul (UFFS) since 2011. Research experience in Mechanical Engineering, with emphasis in Air Pollution Mathematical Models and Atmospheric Boundary Layer Turbulence. Doctorate advisor in Environmental Engineering at Universidade Federal do Espírito Santo (UFES) and Environmental Science and Technology at UFFS. Books published about Micrometeorology. Scholarship in Research Productivity $1 \mathrm{C}$ at CNPq. 